\title{
Learners' Experience Towards e-Assessment Tools: A Comparative Study on Virtual Reality and Moodle Quiz
}

\author{
https://doi.org/10.3991/ijet.v14i05.9998
}

\author{
Ahmed Al-Azawei( $\left.{ }^{(}\right)$,Wadhah R. Baiee, Mustafa A. Mohammed \\ University of Babylon, Babel, Iraq \\ ahmedhabeeb@itnet. uobabylon.edu.iq
}

\begin{abstract}
Although the integration of virtual world in teaching and learning has been investigated, there is a scarcity of research considering its influence on assessing learners' understanding and comparing it with traditional e-assessment tools such as that in Moodle quiz. In this research, a virtual reality (VR) game-based e-assessment application was designed first. Subsequently, the study aims at (1) understanding whether the type of e-assessment method can affect students' performance, and (2) investigating the difference in learners' perceptions based on the type of e-assessment technology. A combination of quasi-pre-test and post-test experimental and survey research design methods were adopted. Overall, 32 undergraduate students were assigned to either control $(\mathrm{N}=17)$ or experimental $(\mathrm{N}=15)$ group. The key findings are (1) no statistical differences in students' performance were found for both groups, and (2) significant differences between learners who completed the VR game-based e-assessment and those on the control group were found on perceived playfulness and ease of use. The conclusion drawn from the research outcomes is that a VR game-based e-assessment application is a successful approach to enhance learners' engagement in evaluation sessions, although students may face a lack of experience in its use.
\end{abstract}

Keywords—Virtual reality, Moodle, E-assessment, Perceived playfulness

\section{Introduction}

The implementation of computer-based assessment technologies has a decadeslong history. According to Alruwais, Wills, and Wald [1], in the 1920's, Sidney Presses designed a machine for automatic testing, to be the first start of e-assessment in education. E-assessment refers to the "end-to-end electronic assessment processes where ICT [information and communication technology] is used for the presentation of assessment activity, and the recording of responses" [2]. It represents a natural partner to e-learning which can offer alignment of teaching, learning, and assessment means [3][4]. In fact, e-assessment is not just much more than what teachers doing in traditional assessment methods. Evidence provided confirms that well-designed and well-applied e-assessment can provide more effective learning [2]. In this present context, e-assessment means assessing learners' knowledge and recording their 
response using two technologies, a developed virtual reality (VR) game application and Moodle e-assessment tool.

Many educational institutions developed and/or adopted different e-assessment systems [1]. Marriott [5] emphasizes that e-assessment can increase learners' motivation which has a positive impact on their academic performance. It is noteworthy that positive learning experience can be only improved when the learning and teaching environment is not classical and thus learners can become more inspired, enthusiastic, and engaged in different learning activities [6]. Many reasons can lead to learners' dissatisfaction on the traditional e-assessment methods such as the lack of concentration and the low level of motivation. However, in the cognitive evaluation theory (CET), it is argued that social-contextual events such as feedback, rewards, and communications that lead to feelings of competence during particular action can improve intrinsic motivation for that particular action [7].

Based on this consideration, there is an insistent need to develop more engaged eassessment methods to motivate learners and improve their learning experience. According to Gee and Shaffer [8], the focus on designing and developing games for teaching and learning should also consider the development of games for assessment. Gamification is a means to improve students' motivation and engagement [9]. This term 'gamification' is defined as the implementation of game design elements in nongame contexts such as health, finance, news, and education [10]. The key aim of gamification is at increasing learner motivation to complete different learning activities such as attending class, practising online discussion, and performing assessments (e.g., extra assignments) [9] [11]. Game-based learning (GBL), on the other hand, refers to providing learners with games that integrate educational goals to be achieved through the gameplay [12]. Game elements, also called game mechanics, are defined as "constructs of rules and feedback loops intended to produce enjoyable gameplay" [13]. Although previous literature has extensively investigated the use of games as an effective way of improving learning outcomes, there are still several aspects that need further research [9].

The present paper, therefore, adds to a few studies on the implications of VR gamebased e-assessment application on evaluating learners' understanding. To the best of the authors' knowledge, there is a scarcity of academic research considering and comparing the impacts of e-assessment on learners' experience using a VR gamebased e-assessment application and Moodle e-assessment tool. It is expected that the integration of VR game into students' evaluation process can improve their motivation to complete their exams successfully. The philosophy behind this assumption is that in this digital age, young students are highly engaged with VR games and, thus, such features can be exploited to avoid the boredom student's face during traditional assessment methods. Hence, this present work can extend previous literature and bridge a research gap regarding the effect of two e-assessment applications on learners' experience in terms of academic performance, ease of use, usefulness, playfulness, and behavioral intention to adopt e-assessment technologies. 


\section{Theoretical Background and the Research Hypotheses}

\subsection{The concept of e-assessment}

Traditionally, e-assessment refers to the use of computer and information technology to perform the assessment process more efficiently. This can be achieved by automating different functions in e-assessment tools and applications that would otherwise need human evaluators. The " $\mathrm{e}$ " in 'e-assessment' includes choosing from a wide variety of information technologies and a computer that can be used as components of the development of assessment, application, and delivery. The "assessment" means the purpose and features of conducting the assessment. Generally, e-assessment should maintain the main characteristics of traditional assessment such as accessibility, reliability, validity, and fairness [14].

Based on previous studies [1][15][16][5], e-assessment has many advantages over the traditional assessment approach. This may include, but are not limited to, providing a direct feedback, this method is fast and enjoyable, it can improve learners' motivation which has a direct effect on their performance, e-assessment reduces the time teachers require marking students' answers, and finally, it is more flexible than the traditional assessment method. On the contrary, e-assessment faces many challenges [1] such as the lack of technology experience, the poor ICT infrastructure, particularly in developing countries, and it is difficult to correct students' response in open-ended questions.

\subsection{Virtual reality (VR)}

The appearance of virtual reality (VR) can be dated back to the 1960's in which it was firstly used in higher education in the early 1990's with several applications such as Safety World, Science Space, and Virtual Gorilla Exhibit Change [17]. According to Rueda, Godínes, and Rueda [18], "VR attempts to create a complete reality, to the exclusion of whatever physical world the person may be located in, the intention being that the person experiences only images, sound, and other sensations, created by the technology" (p.85). The advantages of VR in education may encompass: improving academic achievement, motivating students towards the learning content, providing further interaction methods, moving from a teacher-centered to a studentcentered model, and performing particular experiments regardless of the shortage of equipment [19][20][21][22].

This does not mean that the use of VR applications is without limitations. The financial feasibility is one reason behind the restricted application of VR in education [21]. The other limitation identified is the poor design of the VR instructions [23]. This is in addition to many physical and psychological discomforts such as headset weight and fit, strenuous posture demands, disorientation, dissociation, simulator sickness, and hallucination. Regardless of such issues, the rapid development of computers and digital technologies have led to the VR applications to be deployed in higher education [24]. 


\subsection{Development of the research hypotheses}

The use of multimedia instructions in contemporary education represents a shift in the Web-based learning approaches from traditional multimedia instructions to a more interactive, intuitive, and immersive learning approaches [25]. Here, many studies related to the present research are reviewed as an initial step to build our hypotheses.

Learners' Performance: Earlier literature reports that e-assessment can positively affect learners' achievement [16]. However, it is not clear in previous research whether a particular e-assessment type has a higher impact on performance or not. A meta-analysis review study performed by Merchant et al. [17] on 67 VR papers suggested that "There was statistically no significant difference between the studies in the categories of games or virtual worlds based on the control group treatment.". On the contrary, a study carried out by Chang, Warden and Lin [26] compared the effect of using a digital game and LMS on learners' performance where the findings support the improvement in learning performance by adopting the digital game system. Eassessment applications, however, evaluate learners' knowledge already gained. Hence, it was not assumed here that they will affect learners' knowledge and understanding.

H1: There is no significant difference in learners' performance based on the method of e-assessment.

Perceived Ease of Use. Perceived ease of use refers to the mental effort required to accomplish an action [27]. In the context of technology adoption, studies suggest that to continue using a technology, its use should not require a high mental effort [28][27]. However, the level of such effort is highly affected by users' experience in a particular technology [29][30]. Way [4] found that the lack of experience in eassessment use is a challenge faces both students and teachers to continue adopting eassessment applications. Thus, we expected that students will perceive VR ease of use lower than the Moodle quiz tool.

H2: Learners will rate the ease of use of the Moodle e-assessment tool higher than the VR game-based e-assessment application.

Perceived Usefulness. Perceived usefulness "pertains to user believes that the adoption of a particular technology can improve his/her performance" [31]. Previous literature found that this variable is an important factor to use a particular technology [28][32]. However, perceived usefulness depends on the technology ease of use [27]. Due to the unfamiliarity of the research participants in the use of a VR game-based eassessment application, this research did not assume that learners will perceive the usefulness of this application higher than the Moodle quiz tool.

H3: There is no significant difference in the perceived usefulness of the Moodle and VR e-assessment applications.

Perceived Playfulness. Perceived playfulness means "the perceived hedonic value amplified by fun, excitement, creativity and pleasure accruing from [the] use of the system" [33]. Reid [34] indicated that the implementation of VR applications did foster learners' playfulness in comparison to other learning environments. In line with this research, Parong and Mayer [35] compared the effectiveness of immersive VR against the traditional slideshow as a media of learning. The overall results showed 
that students who used the latter technology performed better, although they were ratings their motivation, interest, and engagement lower than the former group.

Although the above discussed studies emphasize that VR applications can highly engage students in teaching and learning, our research is different from them as it aims at proving the enhancement of learners' motivation and fun by using a particular VR-based game e-assessment technology. Literature has reported a positive connection between the use of games in education and students' engagement [9]. However, there are surprisingly a few number of research that actually investigated engagement in the VR game-based assessment context. Coller and Shernoff [36] showed that students who performed class and labs homework in a game-based approach were more engaged in doing this activity than others who did homework normally. In fact, games are more challenging activities, particularly if they are used in students learning and assessment. As such, it was proposed here that students will enjoy the VR game application more than the Moodle e-assessment tool.

H4: Learners will rate the VR game-based e-assessment playfulness higher than the Moodle e-assessment tool.

Behavioural Intention. It is defined as a user's cognitive representation of his/her willingness to accomplish a certain behaviour [37]. Behavioural intention to accept a particular technology is associated with many cognitive, social, individual, and psychological variables. Perceived enjoyment was found to affect users' willingness to accept a technology [38]. Here, it was assumed that students will have a higher willingness to adopt the VR game-based e-assessment application because it is a new technology introduced in evaluating their knowledge. Furthermore, young students in this digital age are highly engaged by VR game applications.

H5: Learners will have a higher behavioural intention towards the VR game-based e-assessment system than the Moodle e-assessment tool.

\section{Methods}

\subsection{Development of the virtual reality game-based e-assessment application}

In this work, a special VR game-based e-assessment application was developed. It integrates the examination content within the VR world application. The designed system includes a three-dimensional (3D) map of a simple maze. Every part of this game contains a question where students' grades are collected in metrics. The maze includes $n$ number of doors where each door represents one question that can be added by the course teacher. Fig 1 illustrates the designed VR game-based eassessment application, whereas Fig 2 depicts the block diagram of the designed VR game application.

Samsung GEAR VR powered by Oculus with hand control was used to design and test the game. The 3D graphics were created by using Unity $3 \mathrm{D}$ and C\# scripts. The 3D Unity engine was used to create the 3D graphics' items such as the maze, walls, doors, obstacles, items, and players' characters. Each item has its own properties, colors, textures, backgrounds, and metrics. A player's character was designed as eyes 
inside the 3D map to be viewed by a learner using his/her VR tool (mobile, VR Gear, control, and mobile app). Object-Oriented Programming with serialization ability was used as a tool to represent the connection media between the system database and game engine.

In the VR game scenario, players can move towards the doors consecutively to answer the exam questions. A help key was also provided for every door to assist players moving to the next question. This key can be activated after the first wrong attempt for every question. To avoid the player's confusing inside the game, a help character was also provided to work as an indicator for the next question. After the exam time finishing or the player completing all questions, the exam metrics are recorded into users' profiles, including time and scores. These metrics are then recorded into the system database.
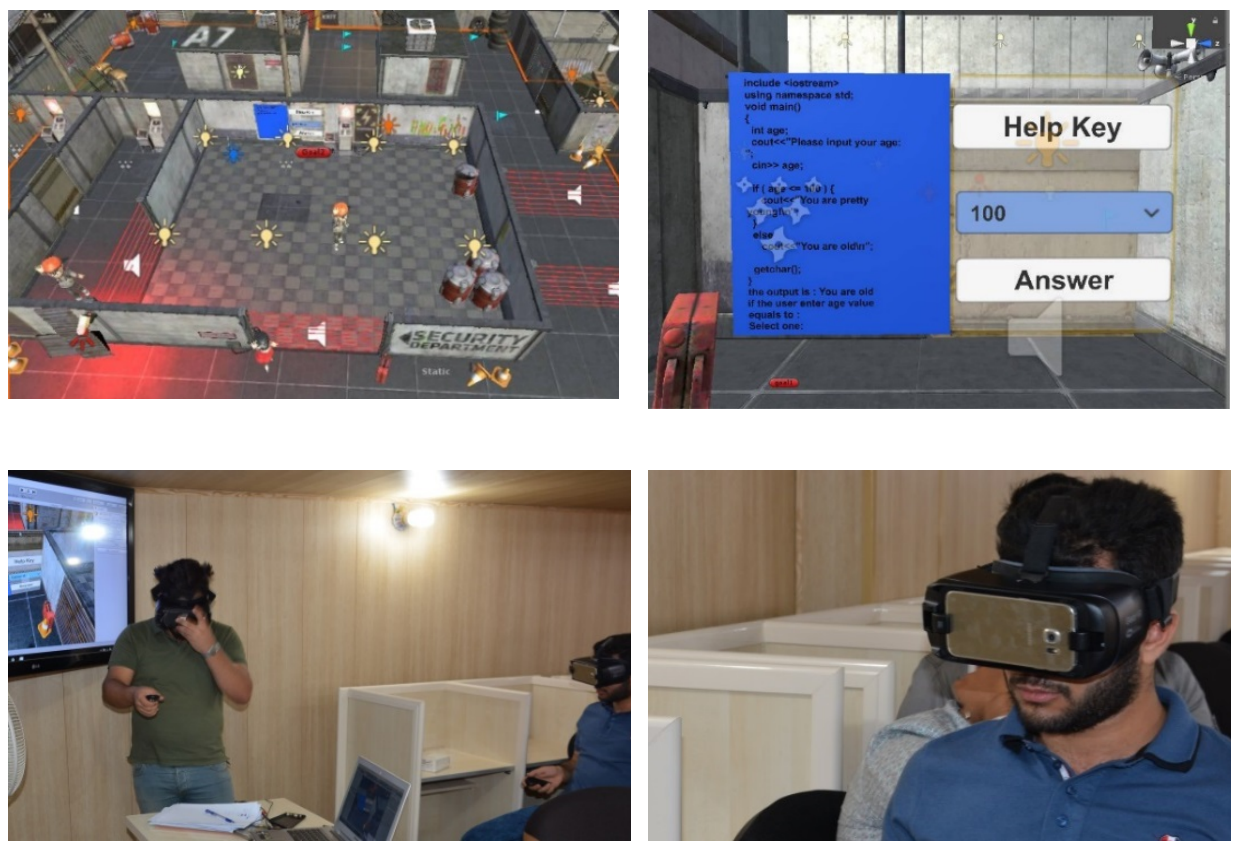

Fig. 1. The design and implementation of the VR game-based e-assessment application 


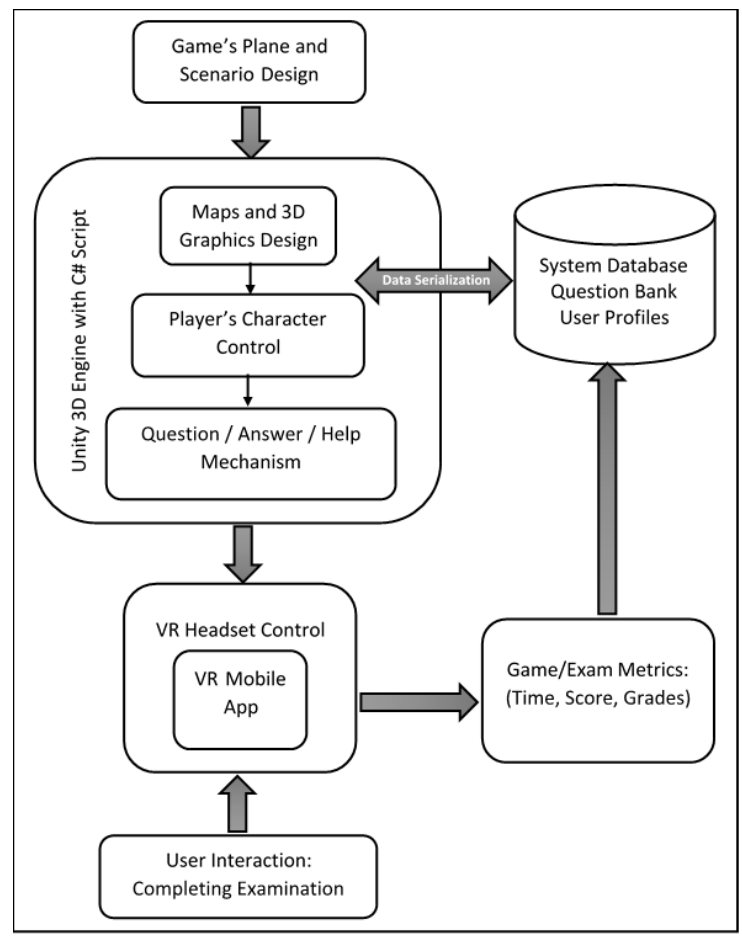

Fig. 2. Block diagram of the developed VR game-based e-assessment application

\subsection{Moodle e-assessment tool}

Quizzes in Moodle are built to provide teachers with the ability to design and apply quizzes online. This e-assessment tool includes a large variety of question types, consisting of true-false, multiple choice, short answer questions and many others [39]. The Question bank is similar to an organized repository where all questions in the course can be saved. These questions can be kept in the question bank and can be reused in different quizzes.

\subsection{Experiment design}

The present study adopted a mixed of pre-test/post-test quasi-experimental and survey research design approaches. This design was used because students could take part in the study at a certain time of their university hours. Accordingly, participants were assigned to either a control or experimental group based on their preference. Both groups performed a paper-based pre-test. It encompassed six questions on different $\mathrm{C}++$ concepts. This is important to ensure that there was no significant difference in the participants overall academic level in $\mathrm{C}++$ language before conducting the post-test. The control group then used Moodle e-assessment tool. The experimental group, on the other hand, did their test using the VR game-based e- 
assessment system. In is noteworthy mentioning that both post-tests included same questions in order to compare students' performance. At the end of both e-tests, the research survey was distributed in which students were requested to express their actual preferences. The experimental design is depicted in Fig 3.

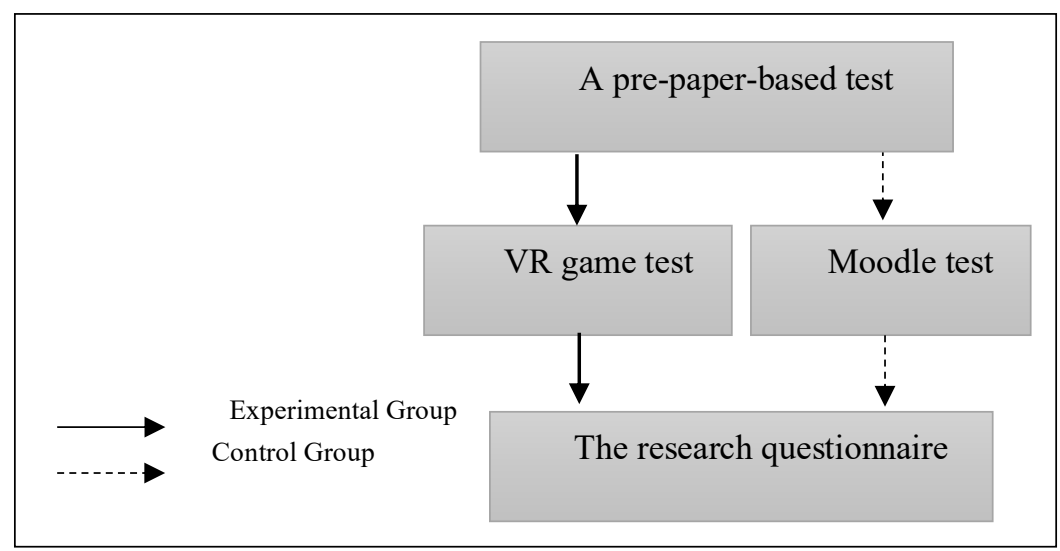

Fig. 3. The design of the research experiment

\subsection{The research context and participants}

This study was carried out at a public university in Iraq. At the end of the second semester of a Programming Fundamentals II course, this study was carried out. Students were taught $\mathrm{C}++$ programming language using a blended learning method. The research subjects were first-year undergraduate Computer Science students. Overall, 32 participants voluntarily took part in the research. The first group (control group) encompassed seventeen students, whereas the second group (experimental group) included fifteen participants. The demographic information of all research subjects is summarized in Table 1.

Table 1. Demographic information of the research subjects

\begin{tabular}{|l|c|c|c|c|c|c|}
\hline \multirow{2}{*}{} & \multicolumn{2}{|c|}{ Gender } & \multicolumn{2}{c|}{ Age } & \multicolumn{2}{c|}{ Technology Experience } \\
\cline { 2 - 7 } & Male & Female & $<=30$ & $>30$ & High & Low \\
\hline Moodle Group & 5 & 12 & 16 & 1 & 5 & 12 \\
\hline VR Group & 11 & 4 & 15 & 0 & 3 & 12 \\
\hline Total & 16 & 16 & 31 & 1 & 8 & 24 \\
\hline
\end{tabular}

\subsection{Data collection}

The research questionnaire: It was mentioned in the cover page of the questionnaire that the participation was voluntary, this experiment was for research purposes only, and nothing of participants' information would be shared with another party. This survey encompassed three parts. The first included questions to collect demographic information of participants. The second consisted of one dichotomy 
question to measure students' experience on e-assessment technology "My experience of using VR (Moodle) in e-assessment is: 1-High 2-Low". The third part measured four variables namely, technology usefulness, technology ease of use, perceived playfulness, and behavioural intention towards technology adoption. This included 19 questions measured based on a five-point Likert scale ranging from 'strongly disagree' to 'strongly agree' (see Appendix).

Technology usefulness variable was measured based on four items adapted from [31]. Technology ease of use factor was assessed based on a scale including three items adapted from [31]. To measure the fun and enjoinment students perceive when they come to use these evaluation techniques, a scale encompassed seven items was used in which it was adapted from [38][40][41]. Finally, to evaluate learners' intention to use either technology, a scale included five items was developed based on a study conducted by Venkatesh, Morris, Davis, and Davis [42].

Feedback session: After performing the research experiment, the authors conducted a feedback session to discuss participants' feedback regarding the use of the developed VR game application. In this session, students were not asked specific questions; however, they were given free time to express their perspectives about the use of this technology in assessing their knowledge.

\subsection{Statistical analysis}

The research analysis was carried out using the statistical package for social science (SPSS) version 21 for Windows 10. The analysis encompassed the computing of means, standard deviation, and independent samples t-test techniques. The independent samples t-tests were performed to investigate the significant difference in students' performance and perceptions based on either e-assessment tool. The significant value of 0.05 or less was adopted in this research $(\mathrm{p}<=0.05)$.

\section{The Research Findings and Discussion}

This study sought to achieve two key objectives. The first was to understand the relation between the type of e-assessment and students' performance. It also aimed to investigate the difference in learners' perceptions based on the type of e-assessment technology (VR game-based e-assessment system and Moodle quiz tool).

\subsection{The measurement features}

To establish the internal consistency reliability of the research questionnaire, Cronbach's alpha $(\alpha)$ and composite reliability (CR) were measured. It is recommended that Cronbach's alpha and CR are acceptable if they exceed 0.7 or 0.6 for Cronbach alpha [43][44]. The study's survey achieved an acceptable and good reliability for all items and for both datasets (see Table 2). 
Table 2. The questionnaire validity and reliability

\begin{tabular}{|l|c|c|c|c|}
\hline & \multicolumn{2}{|c|}{ Moodle quiz dataset } & \multicolumn{2}{c|}{ VR game dataset } \\
\hline & Cronbach's alpha & CR & Cronbach's alpha & CR \\
\hline Performance Expectancy & 0.691 & 0.704 & 0.754 & 0.841 \\
\hline Effort Expectancy & 0.942 & 0.963 & 0.833 & 0.900 \\
\hline Perceived Playfulness & 0.678 & 0.819 & 0.792 & 0.847 \\
\hline Behavioural Intention & 0.829 & 0.924 & 0.776 & 0.828 \\
\hline
\end{tabular}

\subsection{Students' academic achievement}

The first objective was to understand whether learners' performance would be affected by the type of e-assessment method. Prior to conducting the research experiment, a paper-based pre-test was conducted to ensure that there was no significant difference in students' academic level. Table 3 depicts the findings of the independent samples t-test analysis which indicate that the difference in the academic performance for the control and experimental groups were insignificant ( $t$ (30) $=0.153, \mathrm{P}=0.468$ ). Hence, it was rational to investigate the effect of the VR game application and the Moodle quiz tool on learners' performance.

Table 4 shows the difference in students' performance based on the Moodle quiz and the VR game-based e-assessment system. The mean score of the control group is higher than that for the experimental group ( $\mathrm{M}_{\text {Control Group }}=4.216, \mathrm{SD}=1.248$, $\left.\mathrm{M}_{\text {Experimental Group }}=2.333, \mathrm{SD}=1.505\right)$. However, the overall difference was insignificant ( $\mathrm{t}(30)=2.381, \mathrm{P}=0.305)$. This difference in learners' performance may be attributed to the mental effort required to use the VR game-based e-assessment application as mentioned by some students in the feedback session. The participants stated that they found some difficulty to move from one question to another in the VR application. The movement took a quite long time to find the door of the next question to be answered and this, in turn, led to their inability to answer all questions. On the other hand, the control group had an equal opportunity to answer all questions as they previously experienced the Moodle e-assessment tool. This explanation can be further supported by considering the significant difference in the ease of use of the two eassessment tools (see Table 5). Students who used the Moodle tool were rating its ease of use higher than the experimental group.

Table 3. The results of the pre-test assessment (Number of Participants=32)

\begin{tabular}{|l|c|c|c|c|c|c|}
\hline \multirow{2}{*}{ Group } & \multirow{2}{*}{ Number } & \multicolumn{2}{|c|}{ Course results } & \multirow{2}{*}{ t-test } & F & \multirow{2}{*}{ P } \\
\cline { 3 - 4 } & & Mean & SD & & & \\
\hline Control Group & 17 & 3.058 & 1.248 & \multirow{T}{*}{$\mathrm{T}(30)=0.153$} & 0.541 & 0.468 \\
\hline Experimental Group & 15 & 3.133 & 1.505 & & & \\
\hline
\end{tabular}

Table 4. The results of the post-test assessment (Number of Participants=32)

\begin{tabular}{|l|c|c|c|c|c|c|}
\hline \multirow{2}{*}{ Group } & \multirow{2}{*}{ Number } & \multicolumn{2}{|c|}{ Course results } & \multirow{2}{*}{ t-test } & F & P \\
\cline { 3 - 4 } & & Mean & SD & & & \\
\hline Moodle & 17 & 4.216 & 2.508 & \multirow{2}{*}{ T (30) $=2.381$} & 1.090 & 0.305 \\
\hline VR app & 15 & 2.333 & 1.868 & & & \\
\hline
\end{tabular}




\subsection{Differences in students' perceptions}

The second objective was to compare learners' perceptions in the two e-assessment technologies. It is important to understand whether participants had higher perceptions on a particular e-assessment technology over another. This can help educational institutions to implement multiple means of assessments with more focus on a preferable technology by students. The independent samples t-test technique was adopted to investigate the possible difference in learners' perceptions based on the eassessment application. Table 5 depicts the differences in learners' perceptions according to both technologies.

Table 5. The results of learners' perceptions (Number of Participants=32)

\begin{tabular}{|c|c|c|c|c|c|c|}
\hline \multicolumn{7}{|c|}{ Perceived Ease of Use } \\
\hline \multirow[t]{2}{*}{ Group } & \multirow[t]{2}{*}{ Number } & \multicolumn{2}{|c|}{ Course results } & \multirow[t]{2}{*}{ t-test } & \multirow[t]{2}{*}{$\mathbf{F}$} & \multirow[t]{2}{*}{$\mathbf{P}$} \\
\hline & & Mean & $S D$ & & & \\
\hline Moodle & 17 & 3.745 & 0.559 & \multirow[t]{2}{*}{$\mathrm{T}(30)=0.417$} & \multirow[t]{2}{*}{4.111} & \multirow[t]{2}{*}{0.05} \\
\hline VR app & 15 & 3.622 & 1.060 & & & \\
\hline \multicolumn{7}{|c|}{ Perceived Usefulness } \\
\hline \multirow[t]{2}{*}{ Group } & \multirow[t]{2}{*}{ Number } & \multicolumn{2}{|c|}{ Course results } & \multirow[t]{2}{*}{ t-test } & \multirow[t]{2}{*}{$F$} & \multirow[t]{2}{*}{$P$} \\
\hline & & Mean & $S D$ & & & \\
\hline Moodle & 17 & 3.985 & 0.541 & \multirow[t]{2}{*}{$\mathrm{T}(30)=0.172$} & \multirow[t]{2}{*}{0.753} & \multirow[t]{2}{*}{0.393} \\
\hline VR app & 15 & 3.950 & 0.621 & & & \\
\hline \multicolumn{7}{|c|}{ Perceived Playfulness } \\
\hline \multirow[t]{2}{*}{ Group } & \multirow[t]{2}{*}{ Number } & \multicolumn{2}{|c|}{ Course results } & \multirow[t]{2}{*}{ t-test } & \multirow[t]{2}{*}{$F$} & \multirow[t]{2}{*}{$\boldsymbol{P}$} \\
\hline & & Mean & $S D$ & & & \\
\hline Moodle & 17 & 3.605 & 0.344 & \multirow[t]{2}{*}{$\mathrm{T}(30)=2.793$} & \multirow[t]{2}{*}{4.769} & \multirow[t]{2}{*}{0.037} \\
\hline VR app & 15 & 4.114 & 0.657 & & & \\
\hline \multicolumn{7}{|c|}{ Behavioural Intention } \\
\hline \multirow[t]{2}{*}{ Group } & \multirow[t]{2}{*}{ Number } & Couı & & \multirow[t]{2}{*}{ t-test } & \multirow[t]{2}{*}{$\boldsymbol{F}$} & \multirow[t]{2}{*}{$P$} \\
\hline & & Mean & $S D$ & & & \\
\hline Moodle & 17 & 3.788 & 0.712 & $\mathrm{~T}(30)=1.185$ & 0.029 & 0.867 \\
\hline VR app & 15 & 4.080 & 0.675 & & & \\
\hline
\end{tabular}

The first significant difference between the experimental $(\mathrm{N}=15)$ and control $(\mathrm{N}=17)$ groups was reported on learners' motivation and engagement. Participants who attended the VR game-based e-assessment technology were rating perceived playfulness significantly higher than that for the control group. This means that boredom students face during traditional exams may be overcome when the VR game-based e-assessment technology is used. This finding agrees with previous literature found that students who did homework in a game-based format had a higher engagement in comparison to those performed homework normally [36].

Our findings provide empirical support for the conclusion of Marriott [5] that there is a positive association between e-assessment and learners' motivation. This should be reason enough to encourage educational institutions investing more in VR eassessment technologies as they can keep learners engaged and this, in turn, can affect their academic performance. According to Coller and Shernoff [36], "when genuine enjoyment and interest are combined with challenge and concentration, students are 
most likely to be meaningfully engaged in the learning process" (p.315). Furthermore, when learners are interested in a particular activity, they are more likely to insist with its aims and consider it as personally significant [7]. Hence, teachers need to apply a wide variety of assessment methods with more focus on these technologies that meet learners' individual preferences and motivate them such as VR game applications. Effective assessment methods can motivate and engage learners to achieve their goals successfully. Such interactive assessment technologies can be used in short quizzes, self-assessment. and / or learning competitions to and improve students' experience. The effect of the VR game application on students' motivation was also confirmed in their comments:

"I enjoyed using this game where my main constraint was on solving the questions and moving to higher stages."

The other significant difference was found in perceived ease of use. Comparing technology ease of use of students who performed the Moodle e-test with those attending the VR game-based e-assessment system indicates that the former technology was easier to use. This could be obvious because learners have experienced this technology previously as well as its use does not require high mental effort or experience, unlike the VR application. To reduce the amount of effort students require using such technology in their learning activities, it is important to train them beforehand implementing the technology. Thus, training sessions should be conducted to improve learners' self-efficacy and reduce the mental effort required to use that technology. Participants also mentioned that they need further sessions to learn how to use the VR game application.

"It is really enjoyable using this game, however, it is difficult to move to other stages because I have not used it before."

Pertaining to other students' perceptions including, perceived usefulness and behavioural intention towards the technology, participants showed no significant difference in their perceptions and attitudes. This suggests that students had perceived the technology usefulness and willingness to accept the VR and Moodle e-assessment applications similarly. Such outcomes may encourage educational institutions and teachers to exploit the advantages of educational technologies in assessing learners' knowledge and understanding.

\section{Conclusion}

This research was conducted to compare learners' experience in two different eassessment technologies namely, the VR game-based e-assessment system and Moodle quiz tool. Students were divided into two groups in which the first used the Moodle tool, whereas the second used the proposed VR application. A mixed of quasi-pre-test and post-test experimental and survey research design approaches were adopted to meet the research objectives. The main findings of this study suggested that (1) no statistical differences in learners' performance, and (2) significant differences between the control and experimental groups were found on perceived playfulness and technology ease of use. 
Although the present research provides significant findings, it is not without limitations. The first is that the sample size was quite small, whereas incorporating larger sample can provide better results that can be generalized. Thus, replicating the experiment more than once can highlight in more details learners' perceptions and academic performance in the two e-assessment methods. It is hoped that our future research will build on this study findings and overcome its limitations.

\section{References}

[1] N. Alruwais, G. Wills, and M. Wald, "Advantages and Challenges of Using eAssessment," International Journal of Information and Education Technology, vol. 8, no. 1, pp. 34-37, 2018. http://doi.org/10.18178/ijiet.2018.8.1.1008

[2] JISC, "Effective Practice with e-assessment: An overview of technologies, policies and practice in further and higher education," Joint Information Systems Committee (JISC), 2007. [Online]. Available: http://myweb.fsu.edu/vsh ute/pdf/eassessment.pdf.

[3] S. Jordan, "E-assessment: Past , present and future," The Higher Education Academy, vol. 9, no. 1, pp. 87-106, 2013. http://doi.org/10.1 1120/ndir.2013.00009

[4] A. B. Way, "The use of e-assessment in the Nigerian higher education system," Turkish Online Journal of Distance Education, vol. 13, no. 4, pp. 140-152, 2012.

[5] P. Marriott, "Students' evaluation of the use of online summative assessment on an undergraduate financial accounting module," British Journal of Educational Technology, vol. 40, no. 2, pp. 237-254, 2009. https://doi.org/10.1111/j.14678535.2008.00924.x

[6] S. Freeman, S. L. Eddy, M. McDonough, M. K. Smith, N. Okoroafor, H. Jordt, and M. P. Wenderoth, "Active learning increases student performance in science, engineering, and mathematics," Proceedings of the National Academy of Sciences, vol. 111, no. 23, pp. 8410-8415, 2014. http://doi.org/10.1073 /pnas.1319030111

[7] R. M. Ryan and E. L. Deci, "Self-Determination Theory and the Facilitation of Intrinsic Motivation, Social Development, and Well-Being," American Psychological Association, vol. 55, no. 1, pp. 68-78, 2000.

[8] J. P. Gee and D. W. Shaffer, "Looking where the light is bad: Video games and the future of assessment," 2010.

[9] D. Codish and G. Ravid, "Academic Course Gamification: The Art of Perceived Playfulness," Interdisciplinary Journal of E-Learning and Learning Objects, vol. 10, pp. 131-151, 2014. https://doi.org/10.28945/2066

[10] S. Deterding, D. Dixon, R. Khaled, and L. Nacke, "From Game Design Elements to Gamefulness: Defining "Gamification," in Paper presented at the 15th International Academic MindTrek Conference: Envisioning Future Media Environments, 2011. https://doi.org/10.1145/2181037.2181040

[11] F. Wang, Y. Wang, and X. Hu, "Gamification Teaching Reform for Higher Vocational Education in China: A Case Study on Layout and Management of Distribution Center," International Journal of Emerging Technologies in Learning, vol. 12, no. 9, pp. 130-144, 2017. https://doi.org/10.3 991/ijet.v12i09.7493 
[12] B. Kim, H. Park, and Y. Baek, "Not just fun, but serious strategies: Using metacognitive strategies in game-based learning," Computers \& Education, vol. 52, no. 4, pp. 800-810, 2009. http://doi.org/10.1016/j.compedu.2008.12.004

[13] J. M. Kumar and M. Herger, "Interaction Design Foundation," 2018. [Online]. Available: https:/www.interaction-design.org/literature/book/gamification-atwork-designing-engaging-business-software/chapter-6-58-mechanics. [Accessed: 01-Nov-2018].

[14] V. J. Shute, "Simply Assessment," International Journal of Learning, and Media, vol. 1, no. 2, pp. 1-11, 2009. http://doi.org/10.1162/ijlm.2009.0014

[15] M. A. H. Eljinini, S. Alsamarai, S. Hameed, and A. Amawi, "The Impact of Eassessments System on the Success of the Implementation Process," I.J. Modern Education and Computer Science, vol. 11, no. December, pp. 76-84, 2012. http://doi.org/10.5815/ijmecs.2012.11.08

[16] L. Gilbert, D. Whitelock, and V. Gale, "Synthesis Report on Assessment and Feedback with Technology Enhancement," UK, 2011.

[17] Z. Merchant, E. T. Goetz, L. Cifuentes, W. Keeney-kennicutt, and J. Davis, "Effectiveness of virtual reality-based instruction on students' learning outcomes in K-12 and higher education: A meta-analysis," Computers \& Education, vol. 70, pp. 29-40, 2014. http://doi.org/10.1016/j.compedu.2013.07.033

[18] C. J. Á. Rueda, J. C. V. Godínes, and P. D. Rueda, "Categorizing the Educational Affordances of 3 Dimensional Immersive Digital Environments," Journal of Information Technology Education: Innovations in Practice, vol. 17, pp. 83-112, 2018.

[19] J. Chi, C. Hung, and M. Chang, "Integrating video-capture virtual reality technology into a physically interactive learning environment for English learning," Computers \& Education, vol. 55, no. 3, pp. 1346-1356, 2010. http://doi.org/10.1016/j.compedu.2010.06.005

[20] L. Jarmon, T. Traphagan, M. Mayrath, and A. Trivedi, "Virtual world teaching, experiential learning, and assessment: An interdisciplinary communication course in Second Life," Computers \& Education, vol. 53, no. 1, pp. 169-182, 2009. http://doi.org/10.1016/j.compedu.2009.01.010

[21] S. Kluge and L. Riley, "Teaching in Virtual Worlds: Opportunities and Challenges," Issues Informing Science and Information Technology, vol. 5, pp. 127-135, 2008. https://doi.org/10.28945/1000

[22] M. Lou, "A Virtual Reality Teaching System for Graphic Design Course," International Journal of Emerging Technologies in Learning, vol. 12, no. 9, pp. 117-129, 2017. https://doi.org/10.3991/ijet.v12i09.7492

[23] C. J. Chen, S. C. Toh, and W. M. F. Wan Ismail, "Are learning styles relevant to virtual reality?," Journal of Research on Technology in Education, vol. 38, no. 2, pp. 123-141, 2005. http://doi.org/10.1080/15391523.2005.10782453

[24] Y. Zhang, J. Chen, D. Miao, and C. Zhang, "Design and Analysis of an Interactive MOOC Teaching System Based on Virtual Reality," International Journal of Emerging Technologies in Learning, vol. 13, no. 7, pp. 111-123, 2018. https://doi.org/10.3991/ijet.v13i07.8790

[25] H. Huang, U. Rauch, and S. Liaw, "Computers \& Education Investigating learners 'attitudes toward virtual reality learning environments: Based on a constructivist approach," pp. 1-12, 2010.

[26] C. Chang, C. A. Warden, and G. Lin, "Effects of digital game-based learning on achievement, flow and overall cognitive load," Australasian Journal of 
Educational Technology, vol. 34, no. 4, pp. 155-167, 2018. https://doi.org/10.1 4742/ajet.2961

[27] F. D. Davis, R. Bagozzi, and P. R. Warshaw, "User acceptance of computer technology: a comparison of two theoretical models," Management Science, vol. 35, no. 8, pp. 982-1003, 1989. http://www.jstor.org/stable/10.2307/2632151

[28] A. Al-azawei, P. Parslow, and K. Lundqvist, "Investigating the effect of learning styles in a blended e-learning system: An extension of the technology acceptance model ( TAM )," Australasian Journal of Educational Technologies, vol. 33, no. 2, pp. 1-23, 2017.

[29] A. Al-Azawei and K. Lundqvist, "Learner differences in perceived satisfaction of an online learning: An extension to the technology acceptance model in an arabic sample," Electronic Journal of e-Learning, vol. 13, no. 5, 2015.

[30] A. Tarhini, M. Hassouna, and M. S. Abbasi, "Towards the Acceptance of RSS to Support Learning: An empirical study to validate the Technology Acceptance Model in Lebanon," Electronic Journal of e-Learning, vol. 13, no. 1, pp. 30-41, 2015.

[31] A. H. S. Al-Azawei, "Modelling E-Learning Adoption: The Influence of Learning Style and Universal Learning Theories," Doctoral Dessertation, University of Reading, UK, 2017.

[32] C. Weng, C. Tsai, and A. Weng, "Social support as a neglected e-learning motivator affecting trainee's decisions of continuous intentions of usage," Australasian Journal of Educational Technology, vol. 31, no. 2, pp. 177-192, 2015. https://doi.org/10.14742/ajet.1311

[33] H. Çelik, "Influence of social norms, perceived playfulness and online shopping anxiety on customers' adoption of online retail shopping: An empirical study in the Turkish context," International Journal of Retail \& Distribution Management, vol. 39, no. 6, pp. 390-413, 2011. http://doi.org/10.1108/09590551111137967

[34] D. Reid, "The influence of virtual reality on playfulness in children with cerebral palsy: A pilot study," Occupational Therapy International, vol. 11, no. 3, pp. 131-144, 2004. http://doi.org/10.1002/oti.202

[35] J. Parong and R. Mayer, "Learning Science in Immersive Virtual Reality Journal of Educational Psychology," Journal of Educational Psychology, no. 25 January, 2018. http://doi.org/10.1037/edu0000241

[36] B. Coller and D. J. Shernoff, "Video Game-Based Education in Mechanical Engineering: A Look at Student Engagement*," . Int. J. Eng. Educ., vol. 25, no. 2, pp. 308-317, 2009.

[37] I. Ajzen and M. Fishbein, Understanding Attitudes and Predicting Social Behaviour. Prentice-Hall, Inc., Englewood Cliffs, 1980.

[38] M. Atkinson and C. Kydd, "Individual Characteristics Associated with World Wide Web Use: An Empirical Study of Playfulness and Motivation," Data Base For Advances In Information Systems, vol. 28, no. 2, pp. 53-62, 1997. http://doi.org/10.1145/264701.264705

[39] UMassAmherst, "UMassAmherst," 2018. [Online]. Available: https://www.umass.edu/it/support/moodle/overview-quizzes-moodle. [Accessed: 28-Oct-2018].

[40] S. B. Eom and N. Ashill, "The Determinants of Students' Perceived Learning Outcomes and Satisfaction in University Online Education: An Update*," Decis. Sci. J. Innov. Educ., vol. 14, no. 2, pp. 185-215, 2016. https://doi.org/10. $\underline{1111 / \mathrm{dsji} .12097}$ 
[41] F. G. Smith, "Analyzing a College Course That Adheres to the Universal Design for Learning (UDL) Framework.," Journal of the Scholarship of Teaching and Learning, vol. 12, no. 3, pp. 31-61, 2012.

[42] V. Venkatesh, M. G. Morris, G. B. Davis, and F. D. Davis, "User Acceptance of Information Technology: Toward a Unified View," MIS Quarterly, vol. 27, no. 3, pp. 425-478, 2003. http://doi.org/10.2307/30036540

[43] J. F. Hair, W. C. Black, B. J. Babin, R. E. Anderson, and R. L. Tatham, Multivariate data analysis, Six. Upper Saddle River, NJ: Pearson Prentice Hall, 2006.

[44] J. Pallant, SPSS Survival Manual: A step by step guide to data analysis using IBM SPSS, 5th ed. Maidenhead, UK: McGraw- Hill Education, Open University Press: McGrawHill, 2013.

\section{$7 \quad$ Authors}

Ahmed Al-Azawei is the head of Software Department in the College of Information Technology, at the University of Babylon, Iraq. His area of research focuses on learner differences, technology adoption, and Web technologies.

Wadhah R. Baiee is a lecturer in the College of Information Technology, at the University of Babylon, Iraq. He undertook his $\mathrm{PhD}$ in Computer Science at the University of Babylon, Iraq. His area of research focuses on information systems and their applications in GIS.

Mustafa A. Mohammed is a programmer in the College of Information Technology, at the University of Babylon, Iraq. He undertook his BSc in Computer Science at the University of Babylon, Iraq.

Article submitted 2018-12-12. Resubmitted 2019-01-29. Final acceptance 2019-01-30. Final version published as submitted by the authors.

\section{Appendix:}

See next page. 


\section{Appendix: The research questionnaire}

\begin{tabular}{|c|c|}
\hline \multicolumn{2}{|c|}{ Perceived Playfulness (PP) } \\
\hline PP1 & Using VR (Moodle) in e-assessment is fun for me. \\
\hline PP2 & Using VR (Moodle) in e-assessment stimulates my curiosity. \\
\hline PP3 & Using VR (Moodle) in e-assessment leads to my exploration. \\
\hline PP4 & Using VR (Moodle) in e-assessment keeps me happy. \\
\hline PP5 & $\begin{array}{l}\text { Time flies when I am interacting with VR (Moodle) in the } \\
\text { e-assessment session. }\end{array}$ \\
\hline PP6 & $\begin{array}{l}\text { I do not care about outside noise when I am interacting with VR } \\
\text { (Moodle) in the e-assessment session. }\end{array}$ \\
\hline PP7 & $\begin{array}{l}\text { I often forget what I should do when I am interacting with VR } \\
\text { (Moodle) in the e-assessment session. }\end{array}$ \\
\hline \multicolumn{2}{|c|}{ Perceived Usefulness (PU) } \\
\hline PU1 & I believe VR (Moodle) is a useful tool in e-assessment. \\
\hline PU2 & I believe that e-assessment via VR (Moodle) is useful. \\
\hline PU3 & I believe VR (Moodle) improves performance in e-assessment. \\
\hline PU4 & I believe VR (Moodle) is useful in e-assessment. \\
\hline \multicolumn{2}{|c|}{ Perceived Ease of Use (PEoU) } \\
\hline PEoU1 & $\begin{array}{l}\text { I find that all functions are easy to use, even with the limited } \\
\text { experience of using VR (Moodle) in e-assessment. }\end{array}$ \\
\hline PEoU2 & I find that VR (Moodle) can be used easily in e-assessment. \\
\hline PEoU3 & I find it is easy to do what I want on VR (Moodle) in e-assessment. \\
\hline \multicolumn{2}{|c|}{ Behavioural Intention (BI) } \\
\hline BI1 & I tend to use VR (Moodle) in e-assessment in the future. \\
\hline $\mathrm{BI} 2$ & I am likely to use VR (Moodle) in e-assessment in the near future. \\
\hline $\mathrm{BI} 3$ & $\begin{array}{l}\text { Assuming I have access to VR (Moodle) application, I intend to use } \\
\text { it in e-assessment. }\end{array}$ \\
\hline BI4 & I strongly recommend others to use VR (Moodle) in e-assessment. \\
\hline BI5 & $\begin{array}{l}\text { Given that I have access to VR (Moodle), I predict that I will use it } \\
\text { in e-assessment. }\end{array}$ \\
\hline
\end{tabular}

